CASSOWARY volume 4 (1): 87-100

ISSN : 2614-8900

E-ISSN : 2622-6545

Program Pascasarjana Universitas Papua, https://pasca.unipa.ac.id/

\title{
Partisipasi Pedagang Sayur dalam Pengelolaan Sampah Pasar Tradisional Sanggeng di Kabupaten Manokwari
}

\author{
Oktavian Soter $^{1 *}$, Soetjipto Moeljono², Yolanda Holle ${ }^{2}$ \\ ${ }^{1}$ Dinas Pemberdayaan Masyarakat \\ ${ }^{2}$ Program Studi S2 Kehutanan, Program Pascasarjana, Universitas Papua \\ Jalan Gunung Salju Amban, Manokwari, 98314, Papua Barat, Indonesia \\ *Email: viansot112@gmail.com
}

\begin{abstract}
The focus of this research is to examine the participation of traders in market waste management to achieve environmental cleanliness. This is intended so that there is involvement of traders to participate responsibly both actively and passively to achieve environmental cleanliness. This study aims to (1) determine the participation of market vegetable traders in waste management, and (2) analyze the factors that influence the participation of vegetable traders in waste management. The research was conducted at Sanggeng Market as a vegetable trading center in Manokwari Regency. The method used in this research is a survey method with in-depth interview techniques and observation of 52 vegetable traders who trade vegetables at the market of Sanggeng in Manokwari Regency. Data were analyzed using descriptive statistical analysis and inferential statistics. Descriptive statistics used are competency tests and inferential statistics used are Spearman correlation analysis. The results of the study concluded, (1) the participation of vegetable traders shows that they are involved in all stages of waste management, namely the stages of collection, separation, transportation, recycling, and utilization, and (2) there is a correlation between age, education level, acceptance and trading experience.
\end{abstract}

Keywords: trader, market management, trash

\section{PENDAHULUAN}

Sampah merupakan konsekuensi kehidupan yang sering menimbulkan masalah, dan jumlahnya akan semakin meningkat seiring dengan peningkatan jumlah penduduk dan beragam aktivitasnya. Sampah (limbah padat) adalah segala bentuk limbah yang ditimbulkan dari kegiatan manusia maupun binatang yang biasanya berbentuk padat dan secara umum sudah dibuang, tidak bermanfaat atau tidak dibutuhkan lagi Tchobanoglous (1993). Pasar Sanggeng pusat berkumpulnya para penjual dan pembeli, jam operasionalnya dari pagi hingga sore setiap hari. Saat ini pasar Sanggeng belum mempunyai sistem pengelolaan sampah terpadu. Hal tersebut akan mengakibatkan banyaknya jumlah sampah yang dihasilkan dari setiap kegiatan. Sampah yang dihasilkan dari berbagai macam penjualan akan menghasilkan sampah yang beragam pula. Penanganan sampah setiap harinya di pasar Sanggeng untuk saat ini masih menggunakan cara lama yaitu sampah dikumpulkan ke suatu tempat 
pembuangan sampah sementara lalu pada sore harinya sampah diangkut oleh pihak dari dinas kebersihan untuk dibawa ke TPA. Partisipasi pedagang dalam pengelolaan sampah adalah keterlibatan pedagang dalam ikut serta bertanggung jawab baik aktif maupun pasif untuk mewujudkan kebersihan lingkungan. Rumbruren A, Arik et al (2015) data timbunan sampah kabupaten Manokwari akan mencapai $178 \mathrm{~m} 3$ dan setelah dipadatkan, dari volume sampah sebesar $178 \mathrm{~m}^{3}$ maka akan dihasilkan volume sampah padat sebesar $85.44 \mathrm{~m}^{3}$.

Menurut World Health Organization (WHO) dalam Kementrian (2018), bahwa sampah merupakan sesuatu yang tidak digunakan, tidak dipakai, dan tidak disenangi atau sesuatu yang telah dibuang dan berasal dari kegiatan manusia dimana tidak terjadi dengan sendirinya. Sampah dapat dikategorikan kedalam dua jenis yang terdiri atas sampah basah (Garbage) yaitu jenis sampah yang susunannya terdiri atas bahan organik dan mempunyai sifat dapat membusuk atau terurai dengan sendirinya dalam keadaan basah. Sampah kering (Rubbish) yaitu jenis sampah yang susunannya terdiri atas bahan anorganik dan sebagian besar tidak dapat membusuk.

Peningkatan jumlah sampah yang tidak diikuti oleh perbaikan dan peningkatan sarana dan prasarana pengelolaan sampah mengakibatkan permasalahan sampah menjadi kompleks, antara lain sampah tidak terangkut dan terjadi penumpukan sampah dengan sembarangan, kurangnya kesadaran dan kemauan masyarakat dalam mengelola dan membuang sampah, masih kurangnya pemahaman masyarakat tentang manfaat sampah, serta keengganan masyarakat memanfaatkan kembali sampah, karena sampah dianggap sesuatu yang kotor dan harus dibuang. Dengan melihat aktifitas yang banyak terjadi di pasar tradisional dan dimungkinkan volume sampah yang dihasilkan cukup besar maka perlu dilakukan kajian partisipasi pedagang sayur Pasar Sanggeng dalam pengelolaan sampah dengan tujuan (1) Mengetahui partisipasi pedagang sayur pasar dalam pengelolaan sampah, dan (2) menganalisa faktor yang mempengaruhi partisipasi pedagang sayur dalam pengelolaan sampah.

\section{MATERI DAN METODE}

Penelitian ini dirancang secara deskriptif kuantitatif menggunakan metode survey dengan teknik wawancara mendalam dan observasi. Lokasi penelitian di pasar sentra Sanggeng Kabupaten Manokwari. Adapun alasan penetapan lokasi dilakukan secara sengaja dengan alasan wilayah sentra perdagangan sayur mayur di kabupaten Manokwari. Sebagai unit analisis adalah partisipasi pedagang sayur dalam pengelolaan sampah. Subyek penelitian adalah pedagang sayur yang memperdagangkan sayur mayur dengan jumlah responden sebanyak 52 orang. Metode survei menggunakan teknik wawancara mendalam dilakukan untuk menggali informasi secara mendalam dan terbuka tentang topik penelitian. Data adalah unit informasi yang direkam media yang dapat dibedakan dengan data lain, dapat dianalisis dan relevan dengan program tertentu. Pengumpulan data adalah prosedur yang sistematik dan standar untuk memperoleh data yang diperlukan (Ahmad Tanzeh, 2011). Wawancara mendalam dilakukan kepada setiap responden dengan menekankan pada alasan yang terkait dengan partisipasi dan alasan melakukan aktifitas partisipasi.

Adapun alasan penggunaan metode wawancara mendalam dikarenakan responden sangat sensitif (tertutup) dan tersebar. Metode wawancara mendalam di- 
dasarkan atas daftar pertanyaan yang telah dipersiapkan sebelumnya. Menurut Poerwandari (1998) dalam proses wawancara dengan menggunakan pedoman umum wawancara ini, interview dilengkapi pedoman wawancara yang sangat umum, serta mencantumkan isu-isu yang harus diliput tampa menentukan urutan pertanyaan, bahkan mungkin tidak terbentuk pertanyaan yang eksplisit. Metode survei digunakan untuk membuat deskripsi mengenai situasi dari sampel ke populasi sehingga dapat dibuat kesimpulan tentang karakteristik populasi, dan menggunakan kuisioner sebagai alat pengumpul data yang pokok. Survey dilakukan terhadap pedagang sayur yang memperdagangkan sayur mayur padi sawah, dimana metode pengambilan sampel dilakukan secara aksidental sampling. Aksidental sampling adalah tehnik non probabilitas sampling yang mana tehnik penentuan sampel berdasarkan kebetulan, yaitu siapa saja yang secara kebetulan bertemu dengan peneliti dapat digunakan sebagai sampel dimana penentuan orang yang ditemukan pada waktu menentukan sampel cocok dengan yang diperlukan sebagai sumber data. Alasan penggunaan metode aksidental sampling karena: (1) jumlah populasi pedagang sayur di pasar Sanggeng tidak diketahui secara pasti; dan (2) mobilitas responden pedagang sayur di pasar Sanggeng yang tinggi sehingga sulit ditemui. Menurut Nawawi \& Martini (1992) observasi adalah pengamatan dan pencatatan secara sistimatik terhadap unsur-unsur yang tampak dalam suatu gejala atau gejala-gejala dalam objek penelitian. Metode observasi dilakukan untuk melakukan pengamatan secara langsung pada obyek penelitian, guna mengecek kebenaran data secara faktual di lapangan. Komponen observasi meliputi wujud partisipasi dan faktor yang men- dasari wujud partisipasi. Teknik pengumpulan data dilakukan dengan cara perekaman dan pencatatan. Indikator komponen partisipasi pengelolaan sampah terdiri atas 5 (lima) komponen variabel sedangkan indicator faktor yang terkait sebanyak 4 (empat) variabel. Pengukuran perubah menggunakan ukuran skala jenjang dengan pemberian skor satu sampai lima. Metode pengolahan data yang digunakan adalah statistik deskriptif dan statistik inferensial. Statistik deskriptif yang digunakan adalah uji kompetensi dan statistik inferensial yang digunakan adalah analisa korelasi spearman.

\section{HASIL DAN PEMBAHASAN}

\section{Identitas Responden}

Identitas responden digunakan untuk mengetahui keragaman dari responden berdasarkan umur, tingkat pendidikan, penerimaan per hari/bulan dan lama berdagang. Hal tersebut diharapkan dapat memberikan gambaran yang cukup jelas mengenai kondisi dari responden dan kaitannya dengan masalah dan tujuan penelitian, antara lain:

\section{Umur}

Lampus Yuriani (2017) berpendapat bahwa umur seseorang sangat berpengaruh terhadap kemampuan seseorang untuk bekerja secara fisik atau cara berpikirnya. Semakin tinggi umur pedagang akan mengurangi kemampuan dalam bekerja dan cara berpikirnya, sedangkan pedagang yang berumur muda pada umumnya mempunyai kemampuan fisik yang lebih baik maupun cara berpikirnya. Identitas responden berdasarkan umur atau usia dapat ditunjukkan pada Tabel 1. 
Tabel 1. Usia Responden

\begin{tabular}{cccc}
\hline No & Umur (Tahun) & Jumlah Responden (Orang) & Persentase (\%) \\
\hline 1. & $17-25$ & 4 & 7,7 \\
2. & $26-35$ & 10 & 19,2 \\
3. & $36-45$ & 16 & 30,8 \\
4. & $46-55$ & 19 & 36,5 \\
5. & $56-62$ & 3 & 5,8 \\
\hline & Total & 52 & 100 \\
\hline
\end{tabular}

Sumber: Data Primer, 2020

Hasil penelitian berdasarkan Tabel 1 menunjukan jumlah responden pada variabel umur saat dilakukan pengambilan data di lapangan. Umur 17-25 tahun menunjukan presentase yaitu sebanyank 4 responden $(7,7 \%)$ selanjutnya berada pada usia 27-35 tahun menunjukan presentase sebanyak 10 responden $(19,2 \%)$, pada usia 36-45 tahun menunjukan presentase sebanyak 16 responden $(30,8 \%)$, dan pada usia 46-55 tahun menunjukan presentase sebanyak 19 responden (36,5\%), pada usia 56-62 tahun menunjukan presentase sebanyak 3 responden $(5,8 \%)$. Sebagian besar pedagang memiliki usia produktif untuk bekerja sebagai pedagang yang melakukan aktifitas jual beli sayur mayur. Pedagang memiliki kemampuan fisik yang dapat dicurahkan didalam melakukan aktifitas pengelolaan sampah yang dihasilkan.

\section{Tingkat Pendidikan}

Lampus Yuriani (2017) berpendapat bahwa peranan pendidikan formal sangat penting dalam usaha meningkatakan kualitas seseorang karena berguna dalam pembangunan pribadi serta peningkatan intektual dan wawasan seseorang. Selanjutnya, Hasbullah (2009) menyatakan bahwa pendidikan sering diartikan sebagai usaha manusia untuk membina kepribadian sesuai nilai-nilai kebudayaan dan masyarakat dan usaha yang dijalankan oleh seseorang atau kelompok orang lain agar menjadi dewasa atau mencapai tingkat hidup. Berdasarkan hasil observasi dilapangan, bahwa tingkat pendidikan responden bervariasi mulai dari tingkat Sekoah Dasar (SD), SLTP/SMP, SMA, dan tidak bersekolah. Identitas responden berdasarkan tingkat pendidikan dapat ditunjukkan pada Tabel 2.

Komposisi tingkat pendidikan responden dalam tabel 2, menunjukkan responden menurut tingkat pendidikan pedagang sayur. Tidak sekolah berjumlah 6 responden atau $(11,5 \%)$, tingkat pendidikan SD berjumlah 13 responden atau (25\%), tingkat pendidikan SLTP/SMP berjumlah 15 responden atau $(28,8)$ atau $(34,6 \%)$ dan tingkat pendidikan SMA/SMK berjumlah 18 responden atau $(34,6 \%)$. Pedagang memiliki kemampuan intelektual dan berpikir yang cukup baik dalam melakukan aktifitas perdagangan sayur-mayur. Ini berarti didalam melakukan aktifitas dagang menyangkut hal pengambilan keputusan maupun perencanaan perdagangan dan mengelola ssampah yang dihasilkan dapat dilakukan atau dikerjakan oleh pedagang.

\section{Penerimaan Kotor}

Lampus et al (2017), penerimaan atau penghasilan dalam suatu pekerjaan berpengaruh pada seseorang untuk melakukan hal-hal positif dalam suatu pekerjaan seperti halnya berpartisipasi, semakin tinggi penghasilan yang di dapat oleh orang tersebut maka semakin 
tginggi rasa pedulinya terhadap pekerjaan yang dikerjakan. Identitas responden berdasarkan penerimaan atau pendapatan kotor per hari/bulan dapat ditunjukkan pada Tabel 3 .

Tabel 3 menunjukkan penerimaan kotor responden per hari/bulan. Penerimaan Rp.50,000-Rp.90,000 berjumlah 9 orang (17,3\%), Rp.100,000- Rp.180,000 berjumlah 13 orang (25\%), Rp.200,000Rp.280,000 berjumlah 10 orang (19,2\%), Rp.300,000 -Rp.370,000 berjumlah 7 orang $(13,5 \%)$, Rp.400,000-
Rp.450,000 berjumlah 6 orang (11,5\%), Rp.500,000 berjumlah 1 orang (1,9\%), Rp.600,000-Rp.650,000 berjumlah 2 orang $(3,8 \%)$, Rp.750,000 berjumlah 2 orang (3,8\%), Rp.1,500,000 berjumlah 1 orang $(1,9 \%)$ dan Rp. 2,000,000 berjumlah 1 orang $(1,9 \%)$. Hasil penerimaan yang diterima pedagang masih relative rendah. Artinya, hasil usaha sayur mayur belum memberikan pendapatan yang mencukup bagi kebutuhan hidup pedagang sayur.

Tabel 2. Tingkat Pendidikan Responden

\begin{tabular}{cccc}
\hline No & Tingkat Pendidikan & Jumlah Responden (Orang) & Persentase (\%) \\
\hline 1. & Tidak Sekolah & 6 & 11,5 \\
2. & SD & 13 & 25,0 \\
3. & SMP & 15 & 28,8 \\
4. & SMA & 18 & 34,6 \\
\hline & Total & 52 & 100
\end{tabular}

Sumber: Data Primer, 2020

Tabel 3. Penerimaan Kotor per Hari/Bulan Responden

\begin{tabular}{cccc}
\hline No & Penerimaan per Hari/Bulan $(\mathrm{Rp})$ & $\begin{array}{c}\text { Jumlah Responden } \\
(\text { Orang })\end{array}$ & $\begin{array}{c}\text { Persentase } \\
(\%)\end{array}$ \\
\hline 1 & $50,000-90,000$ & 9 & 17,3 \\
2 & $100,000-180,000$ & 13 & 25,0 \\
3 & $200,000-280,000$ & 10 & 19,2 \\
4 & $300,000-370,000$ & 7 & 13,5 \\
5 & $400,000-450,000$ & 6 & 11,5 \\
6 & 500,000 & 1 & 1,9 \\
7 & $600,000-650,000$ & 2 & 3,8 \\
8 & 750,000 & 2 & 3,8 \\
9 & $1,500,000$ & 1 & 1,9 \\
10 & $2,000,000$ & 1 & 1,9 \\
\hline \multicolumn{5}{c}{ Total } & 52 & 100 \\
\hline
\end{tabular}

Sumber: Data Primer, 2020

\section{Lama Berdagang}

Lama berdagang atau usaha menurut Nurani (2010), dalam hal lama usaha ternyata tidak hanya menyangkut jumlah masa kerja saja tapi juga perlu diperhitungkan jenis pekerjaan yang pernah dihadapinya (Tabel 4). Sejalan dengan bertambahnya pengalaman kerja maka akan bertambah pula pengetahuan dan keterampilan seseorang dalam melaksanakan pekerjaannya. 
Tabel 4. Lama Berdagang Responden

\begin{tabular}{cccc}
\hline No & Lama Berdagang (Tahun) & Jumlah Responden (Orang) & Persentase (\%) \\
\hline 1 & $2-4$ & 4 & 7,7 \\
2 & $5-7$ & 16 & 30,8 \\
3 & $8-10,5$ & 14 & 26,9 \\
4 & $11-13$ & 8 & 15,4 \\
5 & $14-17$ & 7 & 13,5 \\
6 & $20-30$ & 3 & 5,8 \\
\hline & Total & 52 & 100
\end{tabular}

Sumber: Data Primer, 2020

Hasil penelitian berdasarkan Tabel 4 diatas menunjukan lama berdagang responden menjadi pedagang sayur di pasar sanggerng manokwari. Lama berdagang 2-4 tahun menunjukan presentase yaitu sebanyank 4 responden $(7,7 \%), 5-7$ tahun menunjukan presentase sebanyak 16 responden $(30,8 \%), 8-10,5$ tahun menunjukan presentase sebanyak 14 responden $(26,9 \%), 11-13$ tahun menunjukan presentase sebanyak 8 responden $(15,4 \%), 14-17$ tahun menunjukan presentase sebanyak 7 responden $(13,5 \%)$ dan 20-30 tahun menunjukan presentase sebanyak 3 responden $(5,8 \%)$. Pedagang sayur belum lama menekuni kegiatan berdagang sehingga pengalaman yang diterima dari lingkungan sekitar dalam aktifitas perdagangan juga belum lama. Situasi ini sangat berkaitan dengan jumlah penerimaan yang relative sedikit yang didapatkan dalam aktifitas perdagangan sayur mayur.

Partisipasi pedagang sayur pasar Sanggeng dalam pengelolaan sampah.

Fahrudin (2011), partisipasi menyangkut keterlibatan masyarakat secara aktif dalam pegambilan keputusan, pelaksanaan, pemeliharaan, evaluasi dan menikmati hasilnya atas suatu usaha perubahan masyarakat yang direncanakan untuk mencapai tujuantujuan masyarakat. Hal yang sama dikemukakan oleh Mubyarto (1985) partisipasi adalah kesadaran untuk membantu berhasilnya setiap program sesuai dengan kemampuan setiap orang tanpa berarti mengorbankan kepentingan diri sendiri.

\section{Partisipasi pedagang sayur pasar tradisional Sanggeng terhadap pengumpulan sampah}

Partisipasi pengumpulan sampah dagangan artinya apakah pedagang melakukan pembersihan sisa potongan sayur, pengumpulan sisa sampah dan menyiapkan wadah penampungan.

Berdasarkan hasil analisis data partisipasi pengumpulan sampah yang disajikan pada tabel 5 Partisipasi pedagang terhadap pembersihan sisa potongan sayur berkategori ST berjumlah 29 orang, T berjumlah 7 orang, $C$ berjumlah 9 orang, $\mathrm{R}$ berjumlah 2 orang, SR berjumlah 5 orang. partisipasi perdagang terhadap pengumpulan sisa sampah berkategori ST berjumlah 30 orang, $\mathrm{T}$ berjumlah 13 orang, $\mathrm{C}$ berjumlah 4 , $\mathrm{R}$ berjumlah 1 orang, SR berjumlah 4 orang. partisipasi pedagang terhadap menyiapkan wadah penampungan berkategori ST berjumlah 3 orang, T berjumlah 38 orang, $\mathrm{C}$ berjumlah 2, SR berjumlah 9 orang. untuk melihat seberapa besar nilai kompetensi partisipasi pedagang sayur terhadap partisipasi pedagang dalam pengumpulan sampah dapat dilihat pada Tabel 6 . 
Partisipasi terkategori tinggi, hal ini disebabkan karena sebagian pedagang menyadari bahwa sampah tidak hanya merusak kelestarian lingkungan, tapi juga mengganggu kesehatan masyarakat, pencemarannya bisa melalui udara, air, tanah, maupun kontak dengan organisme lain yang dapat menimbulkan penyakit. oleh sebab itu dalam melakukan pengumpulan sampah yang dilakukan pedagang selalu mengutamakan kebersihan di sekitar area jualan. ada beberapa pedagang yang melakukan pengumpulan sampah disekitar tempat jualan dan kemudian menampungnya dalam wadah yang telah disiapkan agar terlihat bersih dan memberikan rasa nyaman, tujuannya agar dapat menarik pengunjung untuk membeli hasil jualan mereka.

Tabel 5. Partisipasi Pedagang Terhadap Pengumpulan Sampah per Kategori

\begin{tabular}{llcccccc}
\hline \multirow{2}{*}{ No } & \multirow{2}{*}{ Pengumpulan sampah } & \multicolumn{7}{c}{ Kategori } \\
\cline { 3 - 8 } & & ST & T & C & R & SR & $\Sigma$ \\
\hline 1 & Pembersihan sisa potongan sayur & 29 & 7 & 9 & 2 & 5 & 52 \\
2 & Pengumpulan sisa sampah & 30 & 13 & 4 & 1 & 4 & 52 \\
3 & Menyiapkan wadah penampungan & 3 & 38 & 2 & 0 & 9 & 52 \\
\hline
\end{tabular}

Keterangan: $\mathrm{ST}=$ Sangat Tinggi, $\mathrm{T}=$ Tinggi, $\mathrm{C}=$ Cukup, $\mathrm{R}=$ Rendah, $\mathrm{SR}=$ Sangat Rendah; $\sum=$ Jumlah (Data Primer, 2020)

Tabel 6. Tingkat Partisipasi Pedagang Terhadap Pengumpulan Sampah

\begin{tabular}{|c|c|c|c|c|c|c|c|c|c|}
\hline \multirow{2}{*}{ No } & \multirow{2}{*}{ Pengumpulan sampah } & \multicolumn{8}{|c|}{ Score } \\
\hline & & $\mathrm{n}(\mathrm{ST})$ & $\mathrm{n}(\mathrm{T})$ & $\mathrm{n}(\mathrm{C})$ & $\mathrm{n}(\mathrm{R})$ & $\mathrm{n}(\mathrm{SR})$ & $\sum$ & Tingkat & Ket \\
\hline 1 & $\begin{array}{l}\text { Pembersihan sisa } \\
\text { potongan sayur }\end{array}$ & 145 & 28 & 27 & 4 & 5 & 209 & 4,02 & $\mathrm{~T}$ \\
\hline 2 & $\begin{array}{l}\text { Pengumpulan } \\
\text { sisa sampah }\end{array}$ & 150 & 52 & 12 & 2 & 4 & 220 & 4,23 & ST \\
\hline 3 & $\begin{array}{l}\text { Menyiapkan } \\
\text { wadah penampungan }\end{array}$ & 15 & 152 & 6 & 0 & 9 & 182 & 3,50 & $\mathrm{~T}$ \\
\hline & Total & & & & & & 611 & 11,75 & \\
\hline & Rata-Rata & & & & & & & 3,92 & $\mathrm{~T}$ \\
\hline
\end{tabular}

Keterangan: $\mathrm{ST}=$ Sangat Tinggi, $\mathrm{T}=$ Tinggi, $\mathrm{C}=$ Cukup, $\mathrm{R}=$ Rendah, $\mathrm{SR}=$ Sangat Rendah; $\mathrm{n}=\mathrm{Re}-$ sponden; $\sum=$ Jumlah (Data Primer, 2020)

Partisipasi pedagang sayur pasar tradisional Sanggeng terhadap pemilihan sampah

Partisipasi pengumpulan sampah dagangan artinya apakah pedagang melakukan pemisahan sampah sayur berdasarkan jenis dan penyiapan wadah sampah untuk pemilahan, dapat dilihat pada Tabel 7. Berdasarkan hasil analisis data partisipasi pemilahan sampah yang disajikan pada Tabel 7, partisipasi perdagang terhadap pemisahan sampah sayur berdasarkan jenis berkategori ST berjumlah 8 orang, kategori T berjumlah 3 orang, kategori $\mathrm{C}$ berjumlah 10 orang, kategori R berjumlah 3 orang, kategori SR berjumlah 28 orang. partisipasi perdagang terhadap penyiapan wadah sampah untuk pemilahan berkategori ST berjumlah 2 orang, kategori T berjumlah 33 orang, kategori $\mathrm{C}$ berjumlah 1, kategori SR berjumlah 16 orang. untuk melihat seberapa besar nilai kompetensi partisipasi pedagang sayur terhadap partisipasi pedagang dalam Pemilihan Sampah dapat dilihat pada Tabel 8. 
Tabel 7. Partisipasi Pedagang Terhadap Pemilihan Sampah per Kategori

\begin{tabular}{llccccccc}
\hline \multirow{2}{*}{ No } & \multirow{2}{*}{ Pemilihan sampah } & \multicolumn{7}{c}{ Kategori } \\
\cline { 3 - 8 } & & ST & T & C & R & SR & $\sum$ \\
\hline 1 & Pemisahan sampah sayur berdasarkan jenis & 8 & 3 & 10 & 3 & 28 & 52 \\
2 & Penyiapan wadah sampah untuk pemilahan & 2 & 33 & 1 & 0 & 16 & 52 \\
\hline
\end{tabular}

Keterangan: $\mathrm{ST}=$ Sangat Tinggi, $\mathrm{T}=$ Tinggi, $\mathrm{C}=$ Cukup, $\mathrm{R}=$ Rendah, $\mathrm{SR}=$ Sangat Rendah; $\sum=$ Jumlah Responden (Data Primer, 2020)

Tabel 8. Tingkat Partisipasi Pedagang Terhadap Pemilihan Sampah

\begin{tabular}{|c|c|c|c|c|c|c|c|c|c|}
\hline \multirow{2}{*}{ No } & \multirow{2}{*}{ Pemilihan sampah } & \multicolumn{8}{|c|}{ Score } \\
\hline & & $\mathrm{n}(\mathrm{ST})$ & $\mathrm{n}(\mathrm{T})$ & $\mathrm{n}(\mathrm{C})$ & $\mathrm{n}(\mathrm{R})$ & $\mathrm{n}(\mathrm{SR})$ & $\sum$ & Tingkat & Ket \\
\hline 1 & $\begin{array}{l}\text { Pemisahan sampah } \\
\text { sayur berdasarkan } \\
\text { jenis }\end{array}$ & 40 & 12 & 30 & 6 & 28 & 116 & 2,23 & $\mathrm{R}$ \\
\hline 2 & $\begin{array}{l}\text { Penyiapan wadah } \\
\text { sampah untuk } \\
\text { pemilahan }\end{array}$ & 10 & 132 & 3 & 0 & 16 & 161 & 3,10 & $\mathrm{C}$ \\
\hline & Total & & & & & & 277 & 5,33 & \\
\hline & Rata-Rata & & & & & & & 2,66 & $\mathrm{C}$ \\
\hline
\end{tabular}

Keterangan: $\mathrm{ST}=$ Sangat Tinggi, $\mathrm{T}=$ Tinggi, $\mathrm{C}=$ Cukup, $\mathrm{R}=$ Rendah, $\mathrm{SR}=$ Sangat Rendah; $\mathrm{n}=\mathrm{Re}-$ sponden; $\sum=$ Jumlah (Data Primer, 2020)

Dari hasil observasi di lapangan menunjukan bahwa partisipasi pedagang dalam melakukan pemilahan sampah sudah cukup baik, walaupun masih ada pedagang yang tidak melakukan pemilahan sampah dikarenakan kurangnya kesadaran dalam melakukan pemilahan sampah sayur berdasarkan jenisnya. selain itu pedagang memiliki keterbatasan waktu pada saat menjual hasil dagangan sehingga pedagang hanya fokus pada jualan mereka tanpa memperhatikan kebersihan lingkungan sekitar area jualan. apa bila pedagang melakukan pemilahan sampah, sangat memberi dampak positif bagi lingkungan. salah satu alasannya yakni, sampah yang dipasok ke tempat pembuangan akhir (TPA) bisa berkurang. dimana hal tersebut dapat membuat penggunaan TPA dapat berlangsung lebih lama lagi.

\section{Partisipasi pedagang sayur pasar tradisional Sanggeng terhadap pengangkutan sampah}

Partisipasi pengangkutan sampah dagangan artinya apakah pedagang membayar biaya retribusi, menyiapkan wadah buat sampah yang diangkut dan bayar jasa orang lain, dapat dilihat pada Tabel 9.

Berdasarkan hasil analisis data partisipasi pengangkutan sampah yang disajikan pada tabel 9, partisipasi pedagang terhadap biaya retribusi berkategori ST berjumlah 28 orang, kategori $\mathrm{C}$ berjumlah 8 orang, kategori $\mathrm{R}$ berjumlah 2 orang, kategori SR berjumlah 14 orang. partisipasi pedagang terhadap penyiapan wadah buat sampah yang diangkut berkategori ST berjumlah 2 orang, kategori $\mathrm{T}$ berjumlah 39 orang, kategori $\mathrm{C}$ berjumlah 3 orang, kategori SR berjumlah 33 orang. 
Untuk melihat seberapa besar nilai kompetensi partisipasi pedagang sayur terhadap partisipasi pedagang dalam pengangkutan sampah dapat dilihat pada Tabel 10.

Tabel 9. Partisipasi Pedagang Terhadap Pengangkutan Sampah per Kategori

\begin{tabular}{|c|c|c|c|c|c|c|c|}
\hline \multirow{2}{*}{ No } & \multirow{2}{*}{ Pengangkutan Sampah } & \multicolumn{6}{|c|}{ Kategori } \\
\hline & & ST & $\mathrm{T}$ & $\mathrm{C}$ & $\mathrm{R}$ & SR & $\sum$ \\
\hline 1 & Biaya retribusi & 28 & 0 & 8 & 2 & 14 & 52 \\
\hline 2 & Wadah buat sampah yang diangkut & 2 & 39 & 1 & 0 & 10 & 52 \\
\hline 3 & Bayar jasa orang lain & 11 & 5 & 3 & 0 & 33 & 52 \\
\hline
\end{tabular}

Keterangan: $\mathrm{ST}=$ Sangat Tinggi, $\mathrm{T}=$ Tinggi, $\mathrm{C}=$ Cukup, $\mathrm{R}=$ Rendah, $\mathrm{SR}=$ Sangat Rendah; $\sum=$ Jumlah responden (Data Primer, 2020)

Tabel 10. Tingkat Partisipasi Pedagang terhadap Pengangkutan Sampah

\begin{tabular}{clcccccccc}
\hline \multirow{2}{*}{ No } & \multirow{2}{*}{ Pengangkutan sampah } & \multicolumn{7}{c}{ Score } \\
\cline { 2 - 10 } & & $\mathrm{n}(\mathrm{ST})$ & $\mathrm{n}(\mathrm{T})$ & $\mathrm{n}(\mathrm{C})$ & $\mathrm{n}(\mathrm{R})$ & $\mathrm{n}(\mathrm{SR})$ & $\sum$ & Tingkat & Ket \\
\hline 1 & Biaya retribusi & 140 & 0 & 24 & 4 & 14 & 182 & 3,50 & $\mathrm{~T}$ \\
2 & Wadah buat sampah & 10 & 156 & 3 & 0 & 10 & 179 & 3,44 & $\mathrm{~T}$ \\
& yang diangkut & & & & & & & & \\
3 & Bayar jasa orang lain & 55 & 20 & 9 & 0 & 33 & 117 & 2,25 & $\mathrm{R}$ \\
\hline & Total & & & & & & 478 & 9,19 & \\
\hline & Rata-Rata & & & & & & 3,06 & $\mathrm{C}$ \\
\hline
\end{tabular}

Keterangan: $\mathrm{ST}=$ Sangat Tinggi, $\mathrm{T}=$ Tinggi, $\mathrm{C}=$ Cukup, $\mathrm{R}=$ Rendah, $\mathrm{SR}=$ Sangat Rendah; $\mathrm{n}=\mathrm{Re}-$ sponden; $\sum=$ Jumlah (Data Primer, 2020)

Partisipasi terkategori cukup, hal ini terkait dengan adanya ketersediaan sarana angkutan transportasi pengangkutan sampah yang disediakan pemerintah, dan juga adanya kepedulian pedagang agar sampah tidak dibiarkan tersimpan diareal pasar.

\section{Partisipasi pedagang sayur pasar tradisional Sanggeng terhadap pen- daurulangan sampah}

Partisipasi pendaurulangan sampah dagangan artinya apakah pedagang menyiapkan jenis sampah yang didaur ulang dan menyiapkan lokasi daur ulang.

Berdasarkan hasil analisis data partisipasi pada pendaurulangan sampah yang disajikan pada Tabel 11 bahwa partisipasi pedagang terhadap komponen jenis sampah yang diaur ulang berkategori ST berjumlah 1 orang, kategori $\mathrm{T}$ berjumlah 4 orang, kategori SR berjumlah 46 orang. partisipasi pedagang dalam menyiapkan lokasi daur ulang berkategori ST berjumlah 2 orang, kategori $\mathrm{R}$ berjumlah 1 orang, kategori SR berjumlah 49 orang.

Pada komponen pendaurulangan sampah dapat kita lihat bahwa partisipasi pedagang sangat rendah dalam melakukan daur ulang sampah maupun menyiapkan lokasi untuk daur ulang sampah. Hal ini bisa disebabkan karena kurangnya pengetahuan tentang daur ulang sampah serta belum adanya perhatian dari pemerintah dalam memberikan penyuluhan ataupun sosialisasi terkait pendaurulangan sampah, sehingga banyak pedagang yang belum berpartisipasi dalam pendaurulangan sampah. 
Daur ulang adalah salah satu strategi pengelolaan sampah padat yang terdiri atas kegiatan pemilahan, pengumpulan, pemprosesan, pendistribusian dan pembuatan produk/material bekas pakai, dan komponen utama dalam manajemen sampah modern dan bagian ketiga dalam proses hierarki sampah yang terdiri atas 4R (Reduce, Reuse, Recycle, and Replace).

Tabel 11. Partisipasi Pedagang Terhadap Pendaurulangan Sampah per Kategori

\begin{tabular}{clcccccc}
\hline \multirow{2}{*}{ No } & \multirow{2}{*}{ Pendaurulangan sampah } & \multicolumn{7}{c}{ Kategori } \\
\cline { 2 - 7 } & Jenis sampah yang didaur ulang & 1 & 4 & 1 & 0 & 46 & 52 \\
\hline 1 & Menyiapkan lokasi daur ulang & 2 & 0 & 0 & 1 & 49 & 52 \\
\hline
\end{tabular}

Keterangan: $\mathrm{ST}=$ Sangat Tinggi, $\mathrm{T}=$ Tinggi, $\mathrm{C}=$ Cukup, $\mathrm{R}=$ Rendah, $\mathrm{SR}=$ Sangat Rendah; $\sum=$ Jumlah (Data Primer, 2020)

Tabel 12. Tingkat Partisipasi Pedagang Terhadap Pendaurulangan Sampah

\begin{tabular}{llcccccccc}
\hline \multirow{2}{*}{ No } & Pendaurulangan sampah & \multicolumn{10}{c}{ Score } \\
\cline { 2 - 9 } & $\mathrm{n}(\mathrm{ST})$ & $\mathrm{n}(\mathrm{T})$ & $\mathrm{n}(\mathrm{C})$ & $\mathrm{n}(\mathrm{R})$ & $\mathrm{n}(\mathrm{SR})$ & $\sum$ & Tingkat & Ket \\
\hline 1 & $\begin{array}{l}\text { Jenis sampah yang didaur } \\
\text { ulang }\end{array}$ & 5 & 16 & 3 & 0 & 46 & 70 & 1,35 & $\mathrm{SR}$ \\
2 & $\begin{array}{l}\text { Menyiapkan lokasi daur } \\
\text { ulang }\end{array}$ & 10 & 0 & 0 & 2 & 49 & 61 & 1,17 & $\mathrm{SR}$ \\
\hline Total & & & & & & 131 & 2,52 & \\
\hline Rata-Rata & & & & & & 1,26 & $\mathrm{SR}$ \\
\hline
\end{tabular}

Keterangan: $\mathrm{ST}=$ Sangat Tinggi, $\mathrm{T}=$ Tinggi, $\mathrm{C}=$ Cukup, $\mathrm{R}=$ Rendah, $\mathrm{SR}=$ Sangat Rendah; $\mathrm{n}=\mathrm{Re}-$ sponden; $\sum=$ Jumlah (Data Primer, 2020)

Partisipasi pedagang sayur pasar tradisional Sanggeng terhadap pemanfaatan kembali sampah

Partisipasi pedagang melalui pemanfaatan kembali sampah dagangan artinya apakah pedagang melakukan aktifitas pemanfaatan kembali, pemilahan jenis sampah yang dimanfaatkan dan menyiapkan wadah sampah untuk dimanfatkan.

Berdasarkan hasil analisis data partisipasi pemanfaatan kembali sampah yang disajikan pada Tabel 13 diatas bahwa Partisipasi pedagang terhadap komponen aktifitas pemanfaatan kembali sampah berkategori ST berjumlah 4 orang, kategori $\mathrm{T}$ berjumlah 3 orang, kategori $\mathrm{C}$ berjumlah 13 orang, kategori $\mathrm{R}$ berjumlah 3 orang, kategori SR berjumlah 29. Partisipasi dimanfaatkan berkategori ST berjumlah 22 orang, kategori
$\mathrm{T}$ berjumlah 3 orang, kategori $\mathrm{C}$ berjumlah 4 orang, kategori SR berjumlah 23 orang. partisipasi pedagang terhadap penyiapan wadah untuk dimanfaatkan berkategori ST berjumlah 1, kategori T berjumlah 26 orang, kategori SR berjumlah 25 orang. untuk melihat seberapa besar nilai kompetensi partisipasi pedagang sayur terhadap partisipasi pedagang dalam pengangkutan sampah dapat dilihat pada Tabel 14. 
Tabel 13. Partisipasi Pedagang Terhadap Pemanfaatan Kembali Sampah per Kategori

\begin{tabular}{llcccccc}
\hline \multirow{2}{*}{ No } & \multirow{2}{*}{ Pemanfaatan kembali sampah } & \multicolumn{7}{c}{ Kategori } \\
\cline { 3 - 8 } & & ST & T & C & R & SR & $\Sigma$ \\
\hline 1 & Aktifitas pemanfaatan kembali & 4 & 3 & 13 & 3 & 29 & 52 \\
2 & Jenis sampah yang dimanfaatkan & 22 & 3 & 4 & 0 & 23 & 52 \\
3 & Wadah sampah untuk dimanfatkan & 1 & 26 & 0 & 0 & 25 & 52 \\
\hline
\end{tabular}

Keterangan: $\mathrm{ST}=$ Sangat Tinggi, $\mathrm{T}=$ Tinggi, $\mathrm{C}=$ Cukup, $\mathrm{R}=$ Rendah, $\mathrm{SR}=$ Sangat Rendah; $\sum=$ Jumlah (Data Primer, 2020)

Tabel 14. Tingkat partisipasi pedagang terhadap pemanfaatan kembali sampah

\begin{tabular}{|c|c|c|c|c|c|c|c|c|c|}
\hline \multirow{2}{*}{ No } & \multirow{2}{*}{ Pemanfaatan kembali sampah } & \multicolumn{8}{|c|}{ Score } \\
\hline & & $\mathrm{n}(\mathrm{ST})$ & $\mathrm{n}(\mathrm{T})$ & $\mathrm{n}(\mathrm{C})$ & $\mathrm{n}(\mathrm{R})$ & $\mathrm{n}(\mathrm{SR})$ & $\sum$ & Tingkat & Ket \\
\hline 1 & Aktifitas pemanfaatan kembali & 20 & 12 & 39 & 6 & 29 & $\begin{array}{c}10 \\
6\end{array}$ & 2,04 & $\mathrm{R}$ \\
\hline 2 & $\begin{array}{l}\text { Jenis sampah yang dimanfaat- } \\
\text { kan }\end{array}$ & 110 & 12 & 12 & 0 & 23 & $\begin{array}{c}15 \\
7\end{array}$ & 3,02 & $\mathrm{C}$ \\
\hline \multirow[t]{3}{*}{3} & $\begin{array}{l}\text { Wadah sampah untuk di- } \\
\text { manfatkan }\end{array}$ & 5 & 104 & 0 & 0 & 25 & $\begin{array}{c}13 \\
4 \\
\end{array}$ & 2,58 & $\mathrm{C}$ \\
\hline & Total & & & & & & $\begin{array}{c}39 \\
7 \\
\end{array}$ & 7,63 & \\
\hline & Rata-Rata & & & & & & & 2,54 & $\mathrm{C}$ \\
\hline
\end{tabular}

Keterangan: $\mathrm{ST}=$ Sangat Tinggi, $\mathrm{T}=$ Tinggi, $\mathrm{C}=$ Cukup, $\mathrm{R}=$ Rendah, $\mathrm{SR}=$ Sangat Rendah; $\mathrm{n}=\mathrm{Re}-$ sponden; $\sum=$ Jumlah (Data Primer, 2020)

Dari hasil observasi dilapangan bahwa partisipasi pedagang terhadap komponen pemanfatan kembali sampah sudah cukup baik, artinya sebagian pedagang sudah melakukan pemanfaatan kembali sampah berdasarkan jenisnya. misalnya botol air mineral digunakan kembali untuk mengisi air minum pada waktu berjualan, kantong plastik bekas untuk dijadikan alas tempat duduk. disamping itu ada beberapa pedagang yang belum melakukan hal tersebut dimana pedagang sayur belum memahami tentang sampah apa yang dapat dimanfatkan kembali. Apa bila pedagang sayur di pasar sanggeng sudah di bekali dengan pengetahuan yang cukup melalui sosialisasi atau penyuluhan yang dilaksanakan oleh pemerintah maka akan dapat mengurangi kepadatan sampah pada TPS yang disiapkan sekitar pasar Sanggeng.
Faktor yang mempengaruhi tingkat partisipasi pedagang sayur pasar Sanggeng dalam pengelolaan sampah

Adeviyanti (2013) menyatakan bahwa, beberapa faktor yang dapat mendukung dan menghambat partisipasi masyarakat dalam suatu program yaitu (1) kemauan; (2) kemampuan; dan (3) kesempatan eksternal dan internal. Hasil penelitian uji korelasi spearman antara factor social ekonomi dengan partisipasi disajikan secara terinci.

Umur pedagang sayur sangat berpengaruh pada komponen pengumpulan dan pengangkutan sampah. Dengan demikian sangat dimungkinkan karena pada tahapan tersebut dibutuhkan kemampuan fisik yang harus dicurahkan dengan umur produktif bagi setiap pedagang untuk melakukan pengelolaan sampah. hasil penelitian ini menunjukan bahwa faktor pendidikan yang dikatakan rendah yaitu mulai dari tingkat SD-SMP, faktor pendidikan sebagai penentu dalam pola 
berpikir dan pemahaman pedagang dalam melakukan pemilahan sampah berdasarkan jenis, jadi pedagang yang mempunyai latar belakang pendidikan rendah kebanyakan tidak memikirkan cara untuk memilah sampah dengan baik, hal ini disebabkan karena tidak mengerti manfaat yang dihasilkan setelah melakukan pemilahan sampah tersebut. sedangkan pendidikan tinggi mulai dari tingkat SMA - perguruan tinggi, dimana semakin tinggi tingkat pendidikan yang dimiliki seseorang maka semakin tinggi pula cara berpikir dan pemahaman seseorang dalam melakukan usaha pemilahan sampah dengan lebih baik. Hal ini disebabkan karena kedua variabel responden yang pengetahuannya baik ada yang pengelolaan sampahnya buruk, tetapi responden yang pengetahuannya kurang baik ada yang pengelolaan sampahnya sudah baik. Tahapan daur ulang dan pemanfaatan sampah tidak memberikan pengaruh dalam aktifitas pengelolaan sampah oleh pedagang sayur. artinya, sampah yang dihasilkan dalam kegiatan dagang tidak memiliki nilai manfaat yang dapat dikelola agar menghasilkan penerimaan. nilai manfaat ini berkaitan dengan pengetahuan pedagang yang belum mengetahui teknologi daur ulang sampah yang dihasilkan. Poniwati dan Asmie. (2008) mengemukakan bahwa, pengetahuan masyarakat mengenai pengelolaan sampah akan menentukan tingkat partisipasi masyarakat dalam mengelola sampah untuk menjaga kebersihan lingkungannya.

Tabel 15. Hasil Uji Korelasi Spearman Rho

\begin{tabular}{|c|c|c|c|c|c|c|}
\hline \multicolumn{7}{|c|}{ Correlations } \\
\hline & & $\begin{array}{r}\text { kum- } \\
\text { pul }\end{array}$ & pilah_smph & p_angkut & daur_ulg & pmfaatan \\
\hline \multirow[t]{3}{*}{ Umur } & $\begin{array}{l}\text { Correlation Co- } \\
\text { efficient }\end{array}$ & $.410^{* *}$ & ,214 & $.430^{* *}$ &,- 140 &, 026 \\
\hline & Sig. (2-tailed) & ,003 & ,128 & 001 & .580 & ,856 \\
\hline & $\mathrm{N}$ & 52 & 52 & 52 & 18 & 52 \\
\hline \multirow[t]{3}{*}{ Pendidikan } & $\begin{array}{l}\text { Correlation Co- } \\
\text { efficient }\end{array}$ & $.324^{*}$ & $.319^{*}$ &, 142 &,- 379 & $.310^{*}$ \\
\hline & Sig. (2-tailed) &, 019 & ,021 & ,314 & ,121 &, 026 \\
\hline & $\mathrm{N}$ & 52 & 52 & 52 & 18 & 52 \\
\hline \multirow[t]{3}{*}{ Penerimaan } & $\begin{array}{l}\text { Correlation Co- } \\
\text { efficient }\end{array}$ & $.346^{*}$ & ,274 & $.441^{* *}$ &,- 189 &,- 035 \\
\hline & Sig. (2-tailed) &, 012 & ,052 & ,001 & ,453 & 807 \\
\hline & $\mathrm{N}$ & 52 & 52 & 52 & 18 & 52 \\
\hline \multirow[t]{3}{*}{$\begin{array}{l}\text { Lama } \\
\text { berdagang }\end{array}$} & $\begin{array}{l}\text { Correlation Co- } \\
\text { efficient }\end{array}$ & $.489^{* *}$ &, 224 & $.457^{* *}$ & $-.364^{*}$ &,- 064 \\
\hline & Sig. (2-tailed) &, 000 & ,081 & ,0001 & ,138 & ,653 \\
\hline & $\mathrm{N}$ & 52 & 52 & 52 & 18 & 52 \\
\hline
\end{tabular}

**. Correlation is significant at the 0.01 level (2-tailed).

* . Correlation is significant at the 0.05 level (2-tailed).

Pengalaman berdagang memberikan pengaruh terbesar terhadap tahapan pengumpulan dan pengangkutan. Kondisi ini dapat dijelaskan bahwa, melalui pengalaman berdagang yang diterima dari lingkungan sekitar pasar, maka pedagang akan semakin memiliki wawasan berpikir dan pengambilan keputusan yang tepat dalam aktifitas pengelolaan sampah. tahap pengumpulan sampah 
merupakan tahapan penting yang membutuhkan situasi lingkungan yang bersih dan nyaman bagi pedagang untuk mempersiapkan lingkungan yang sehat bagi pembeli. kejadian yang sama pada tahap pengangkutan sampah, dimana hasil-hasil sampah yang berada di lokasi perdagangan harus dipisahkan dari lokasi yang telah dibersihkan pada areal perdagangan. kondisi tersebut akan memberikan lingkungan yang sehat bagi pedagang dalam menjual dagangannya dan menawarkan lingkungan yang sehat untuk menarik konsumen.

\section{KESIMPULAN}

Berdasarkan hasil dan pembahasan yang dilakukan, maka dapat disimpulkan bahwa nilai total kompetensi partisipasi pedagang terhadap pengumpulan sampah berdasarkan kategori skore sebesar 611 dan nilai total tingkat partisipasi sebesar 11,75 dengan nilai rata-rata tingkat partisipasi sebesar 3,92 terkategori tinggi. Nilai total kompetensi partisipasi pedagang terhadap pemilahan sampah berdasarkan kategori skore sebesar 277 dan nilai total tingkat partisipasi sebesar 5,33 dengan nilai rata-rata tingkat partisipasi sebesar 2,66 terkategori cukup. Nilai total kompetensi partisipasi pedagang terhadap pendaurulangan sampah berdasarkan kategori skore sebesar 131 dan nilai total tingkat partisipasi sebesar 2.52 dengan nilai rata-rata tingkat partisipasi sebesar 1,26 terkategori sangat rendah. Nilai total kompetensi partisipasi pedagang terhadap pengangkutan sampah berdasarkan kategori skore sebesar 478 dan nilai total tingkat partisipasi sebesar 9,19 dengan nilai rata-rata tingkat partisipasi sebesar 3,06 terkategori cukup.

Nilai total kompetensi partisipasi pedagang terhadap pemanfaatan kembali sampah berdasarkan kategori skore sebesar 397 dan nilai total tingkat partisipasi sebesar 7,63 dengan nilai rata-rata tingkat partisipasi sebesar 2,54 terkategori cukup. Terdapat hubungan pengaruh yang signifikan antara variabel umur dengan tahap pengumpulan dan pengangkutan sampah. hubungan pengaruh yang signifikan antara variabel pendidikan dengan tahap pengumpulan, pemilihan, dan pemanfaatan sampah. hubungan pengaruh yang signifikan antara variabel penerimaan dengan tahap pengumpulan dan pengangkutan. hubungan pengaruh yang signifikan antara variabel lama usaha berdagang dengan tahap pengumpulan, pengangkutan dan daur ulang.

\section{SARAN}

Perlu adanya sosialisasi atau penyuluhan dari Pemerintah Daerah kepada pedagang pasar Sanggeng terkait dengan pengelolaan sampah pasar. Pemerintah Daerah dalam hal ini Organisasi Perangkat Daerah agar selalu memberikan sosialisasi kepada pedagang pasar terkait dampak yang ditimbulkan dari sampah yang menumpuk dan menimbulkan aroma tidak sedap sehingga sangat membahayakan bagi kesehatan manusia, lingkungan sekitarnya serta keadaan sosial dan ekonomi.

\section{DAFTAR PUSTAKA}

Adeviyanti, D. (2013). Studi Tentang Partisipasi Masyarakat Dalam Pembangunan Di Kelurahan Karang Jati Kecamatan Balikpapan Tengah. eJournal Administrasi Negara.

Ahmad, T. (2011). Metodologi Penelitian Praktis. Yogyakarta: Teras.

Fahrudin, A. (2006). Pemberdayaan, Partisipasi, \& Penguatan Kapasitas Masyarakat. Bandung: Humaniora. 
Hasbullah. (2009). Dasar-dasar Ilmu Pendidikan. Jakarta: PT. Raja Grafindo Persada

Kementerian Lingkungan Hidup dan Kehutanan RI. (2018). Statistik Lingkungan Hidup Indonesia: Pengelolaan Sampah Di Indonesia.

Mubyarto. (1997). Ekonomi Rakyat, Program IDT, dan Demokrasi Ekonomi. Indonesia. Yogyakarta: Aditya Media.

Nawawi \& M. Martini. (1992). Instrumen Penelitian Bidang Sosial. Yogyakarta: Gadjah Mada University Press.

Poerwandari, E. K. (1998). Pendekatan Kualitatif Dalam penelitian Psikologi. Jakarta: Lembaga Pengembangan Sarana Pengukuran dan Pendidikan.

Poniwati, A. (2008). Analisis FaktorFaktor Yang Mempengaruhi Tingkat Pendapatan Pedagang Pasar
Tradisional di Kota Yogyakarta. Yogyakarta: Universitas Gajah Mada.

Rumbruren A, A. (2015). Evaluasi Kelayakan Lokasi Tempat Pembuangan Akhir Sampah Di Kecamatan Manokwari Selatan.

Tchobanoglous. (1993). Integrated Solid Waste Management Engineering Principles and Management Issues. New York: Mc Graw Hill Inc.

Lampus, Y. (2017). Partisipasi Pedagang Dalam Pengelolaan Sampah. Agri-Sosio Ekonomi Unsrat, ISSN 1907- 4298, Volume 13 Nomor 2A, Juli 2017: 243 - 252. 